\title{
Development of Smart Cities in India - Dream to Reality
}

\author{
Pranav Suresh \\ Indian Institute of Technology, Patna, India. \\ Suresh Ramachandran \\ MARG Institute of Design \& Architecture Swarnabhoomi (MIDAS), India.
}

(๑) Scholedge International Journal of Business Policy \& Governance (ISSN 2394-3351), Vol.03, Issue 06 (2016) pg 73-81. Published by: Scholedge R\&D Center [www.theSCHOLEDGE.org] [Email: editorial@thescholedge.org]

\begin{abstract}
Cities are engines of growth that would be driving India's transformation into a developed economy. With India set to become the youngest country in the world by 2020 requiring 10 to 12 million new jobs every year, the government has initiated The Smart Cities Mission to promote large scale planned urbanisation to create conducive atmosphere for promoting accelerated growth and development. As India embarks on this journey to create engines of growth to drive the country's development this paper outlines the path for making this dream a reality. The paper puts forward strategies for planned urbanisation, guidelines for smart city development and elaborates on the toughest summits to peak in this quest to transform urban India.
\end{abstract}

Keywords: Smart Cities, India, Urbanisation, Infrastructure, Development

\section{Introduction}

According to the Census of India Report the urban population of India has risen from 286 million in 2001 to 377 million in 2011 and this spurt will increase exponentially by 2030, the McKinsey Global Institute estimates that the urban population would soar further and reach a whopping 590 million housing 4oper cent of the Indian population and contributing to 75per cent of the nation's GDP. Since, the agrarian model of Indian economy is rapidly turning dependent on industrialization there is huge migration of rural dwellers not only towards state capitals and economic hotbeds, but also towards tier-II and tier-III cities. These towns and cities offer huge job potential and space for capitalists to intensify their business operations. The unprecedented increase in urban population is already putting tremendous pressure on existing infrastructure and calls for a large scale capacity expansion of infrastructure services and urban developments to accommodate and provide better living standards for the migrating population. The urban developments have to be comprehensive including the development of physical, institutional, social and economic infrastructure. Comprehensive development is important in improving the quality of life and attracting people and investments to the city, setting in motion a virtuous cycle of growth and development. Smart cities are urban eco-systems which are represented by these four pillars of comprehensive development.

Smart cities broadly identify themselves with eight key features: good governance, adequate energy availability and efficient energy usage, smart buildings, required infrastructure services with good network of roads and integrated public transport systems, robust technological connectivity, affordable and good quality healthcare and a sustainable \& healthy environment. 


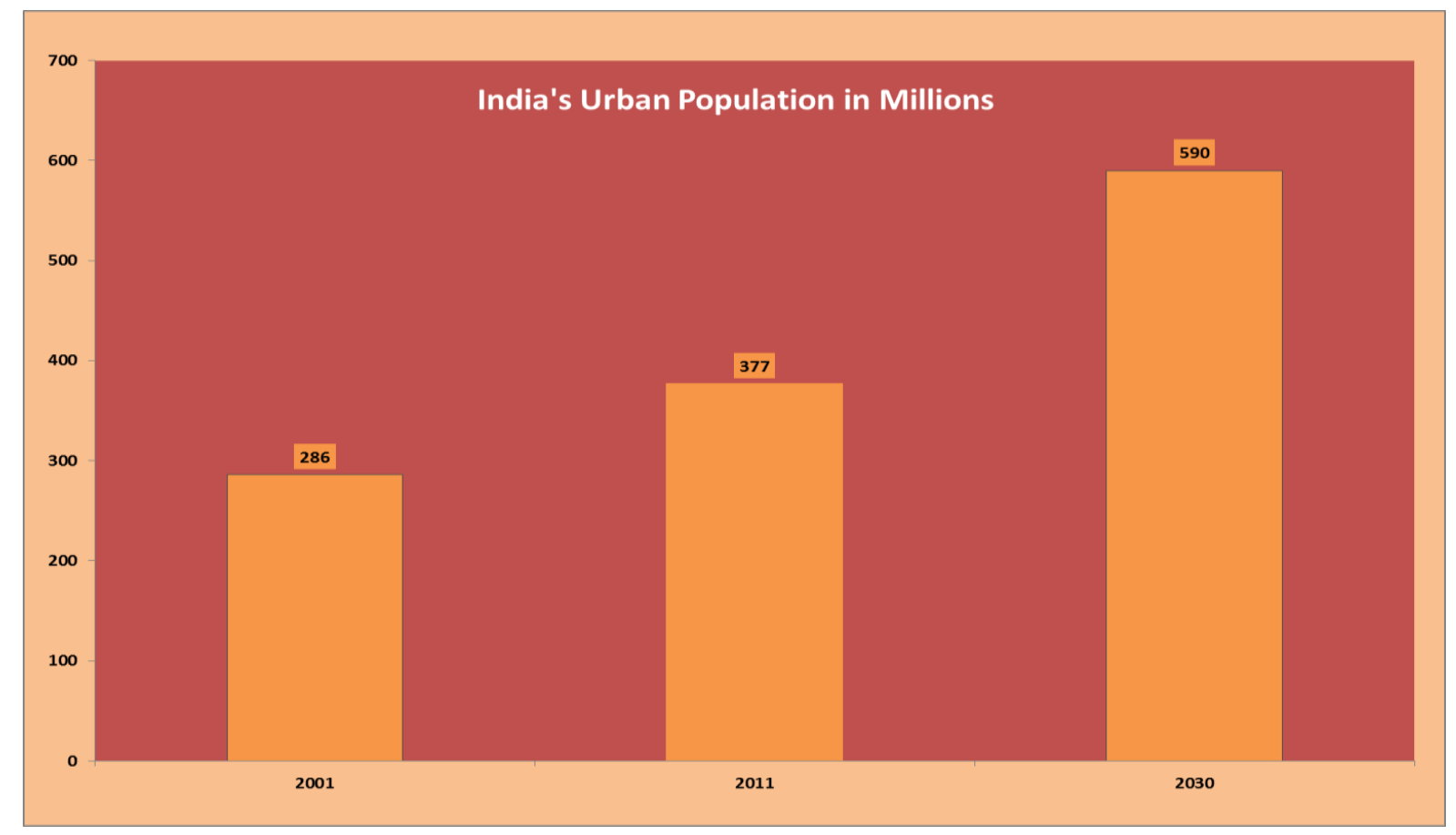

The Indian Government under the leadership of our Prime Minister Narendra Modi has initiated the 'Smart Cities Mission' - a urban renewal and retrofitting program with a mission to develop 100 cities all over the country in the next five years (FY 2015-16 to FY 2019-20) making them citizen friendly and sustainable.

\section{Area based developmental strategies}

A comprehensive urbanization strategy is essential to make the most of this push for smarter cities in our country and create truly revolutionised cities for future India. The following are the three main area based development strategies:

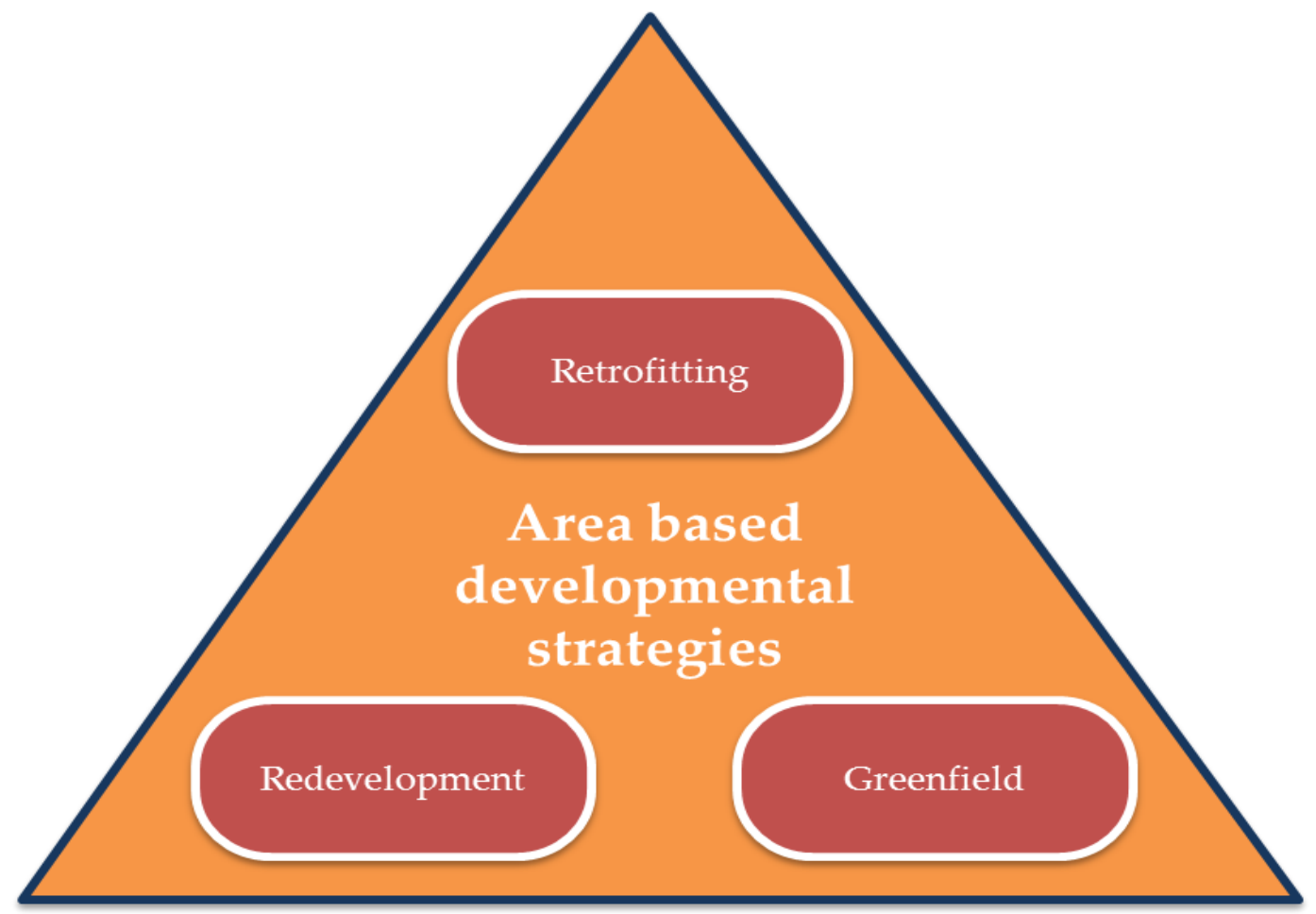




\section{Retrofitting}

The 'Smart Cities Mission' principally involves brownfield developments and is not focused on creating new cities. This makes retrofitting a very significant area-developmental strategy where existing built up areas are retrofitted to make them more efficient and liveable.

Globalisation and the conscious shift towards a knowledge and information-based economy are resulting in the emergence of 'Digital Urbanism' which is an understanding of city life shaped by the influx and pervasiveness of digital technologies. It is the new-age mantra for urban developments and is at the core of a smart city. Smart cities are envisioned to use ICT (Information and Communications Technology) to enhance its liveability, workability and sustainability by collecting, communicating and compiling data. Digital technologies fuel intelligent automation which would help cities perform better socially, economically and environmentally. Sensor embedded water pipes would reduce water wastage, occupancy and photo sensors coupled with largescale LED retrofits can help reduce power consumption and increase energy efficiency. Implementation of zero emission strategies like the recent introduction of Chinese manufacturer BYD's zero-emission, pureelectric buses would help reduce pollution levels and carbon footprints helping us move towards making our cities cleaner and sustainable.

The main objective of retrofitting would be to equip existing infrastructure to meet smart city objectives and prepare them for the techno-centric era.

\section{Redevelopment}

Most Indian metros are more than a century old and have witnessed unparalleled inflow of migrants giving rise to large scale unplanned developments in its prime pockets. The cities are growing in a haphazard manner and create irreversible unplanned developments that have detrimental effects in all fronts making future integration of infrastructure practically impossible. Bengaluru, Delhi and Mumbai are all having serious problems because of unplanned developments.

Redevelopment will effect a replacement of the existing built-up environment and enable co-creation of a new layout with enhanced infrastructure using mixed land-use and increased density. Promoting mixed land-use is again at the core of a smart city; it would physically and functionally blend residential, commercial, cultural, institutional and industrial land pockets.

The potential benefits of redevelopment in a city are many. It not only reduces urban sprawl but also improves the economic competitiveness of city. Redevelopment of the road network and creation of Bus Rapid Transit Systems (BRTS) is an efficient, high capacity and cost effective transit solution to meet the infrastructure needs. Many Indian Cities such as Ahmedabad, Delhi and Jaipur have developed relatively large BRTS networks. Well-planned and delivered BRT systems with clean buses can provide 'metro-quality' service at a fraction of the cost and would be viable solutions to move large amounts of people smartly in a clean and lean way.

When it comes to redevelopment of buildings the focus must be on cluster redevelopment rather than the individual redevelopment of buildings. Cluster redevelopment is the redevelopment of a group of dilapidated structures and inadequate \& deteriorated amenities and services into a state-of-the-art sustainable development with new buildings, wide roads and modern infrastructure to meet smart city objectives. While redevelopment would help modernise infrastructure focus should also be on incorporating of historic structures into new and rehabilitated development. In most Indian cities like Mumbai, Delhi, Chennai which have rich cultural, historical and community assets it is important to preserve and enhance them. The cultural fabric of the community must not be compromised, if not enhanced. The Saifee Burhani Upliftment Project in Mumbai and the redevelopment of East Kidwai Nagar in New Delhi are some pilot cluster redevelopment projects which are critical trend setters. The very recent approval of the Maharashtra State Government of a cluster development policy for Thane is a clear indicator that cluster-redevelopment is a critical area 
developmental strategy for making our cities smarter by promoting mixed land-use, higher FSI (Floor Space Index) and high ground coverage.

\section{Greenfield developments}

The 'Smart Cities Mission' includes the urban renewal of a large share of Tier-II and Tier-III cities in the country. These cities are not as congested as the metros at present but the expanding urban population would promote vast amounts of Greenfield Developments in vacant lands of the city's suburbs. These developments need to be planned holistically taking advantage of the latest developments in technology, focussing on creating employment opportunities and supporting economic activities that will improve quality of life for citizens.

The primary task of the urban planners would be the development of basic physical infrastructures such as roads, power, water supply, sewerage, and waste management systems that are Blue-Green. Blue-green infrastructures which amalgamate efficient water management and green infrastructure by combining and protecting the hydrological and ecological values of the urban landscape while providing resilient and adaptive measures to address future changes in climate, land use, water management, and socio-economic activity in the city would be critical in addressing problems of water scarcity that is plaguing most Indian cities. Blue-Green Infrastructure aims to reintroduce the natural water cycle into urban environments and provide effective measures to manage fluvial (river), coastal, and pluvial (urban runoff or surface water) flooding while championing the concept of multi-functional greenspace and land use to generate multiple benefits for the environment, society, and the economy.

The public transit system created must focus on last mile connectivity and modal integration not just within the new developments but with older parts of the city as well. The public transport systems between them must be capable of moving maximum amount of people in the shortest possible time at the cheapest costs from within one mile of their origin to within one mile of their destination using the least amount of energy. Increased investment in public transport systems and a focus on transit-oriented development (TOD) are necessary to make cities more energy efficient, better connected, and less polluted. TODs are mixed-use residential and commercial areas designed to maximise access to public transport, and often incorporate features to encourage transit ridership.

With about two millions houses required to be developed every year typically in the affordable housing category the greenfield developments must be planned to create enough affordable houses for the poor.

All in all, Greenfield developments must gel innovative design and planning introducing smart solutions to create resilient infrastructure that define smart cities.

\section{Guidelines for the development of smart cities}

The Ministry of Urban Development does not prescribe any specific model which has to be strictly adopted but has put forward basic guidelines for the development of smart cities.

\section{Formulation of the concept}

The opening objective would be to for the state to select some cities to be refurbished and formulate the concept, vision, mission and plan of the smart city weighing the local contexts, the resources available and ambition levels. Following this the Smart City Proposal (SCP) would have to be developed by the state containing the vision, plan for mobilisation of resources and intended outcomes in terms of infrastructure up-gradation and smart applications.

\section{Essential Features of a Smart City}

The following features must be incorporated in the model as per Ministry of Urban Development's norms. The Smart City must have assured electricity supply with at least 10per cent of the city's energy requirement coming from solar, adequate water supply including 
waste water recycling and storm water reuse, sanitation including solid waste management, rain water harvesting, smart metering, robust IT connectivity and digitalization, pedestrian friendly pathways, encouragement to non-motorised transport (e.g. walking and cycling), intelligent traffic management, non-vehicle streets/zones, smart parking, energy efficient street lighting, innovative use of open spaces, visible improvement in the area (e.g. replacing overhead electric wiring with underground wiring, encroachment-free public areas, and ensuring safety of citizens especially children, women and elderly). In the case of redevelopment and Greenfield models of Smart Cities at least 8 oper cent buildings should be energy efficient and green buildings and at least 15per cent of the housing provided in Greenfield developments must fall under the affordable housing category.

\section{Development of the smart city}

The various SCPs containing area based development plans prepared with the assistance of the consultants and handholding agencies would be assessed and evaluated at various levels before being ultimately selected for implementation. The cities then would have to setup a Special Purpose Vehicle (SPV) to implement the SCPs at a city level by planning, appraising, approving \& releasing funds, implementing, managing, operating, monitoring and evaluating the project monitoring and aiding the execution various contractors through joint ventures, subsidiaries, public-private partnership (PPP), turnkey contracts etc. The success of this endeavour will depend on the robustness of the SPV's revenue model and the comfort it provides to the lenders and the investors.

\section{Challenges in making smart cities operational and successful}

As India embarks on this ambitious mission to transform the urban space of our country, the following are some of the biggest challenges that have to be conquered to make the Smart Cities Mission a success

\section{Financing}

The smart city concept heavily relies on ICT-enabled service delivery mechanisms with the core objective of providing better city infrastructure through integrated systems, expenditure on technology upgrades and basic infrastructure of 100 cities in such a short timeframe will be a costly affair for the government and beyond its financial capabilities. This would involve not only capital investments for setting this up, but also substantial operations and maintenance costs. According to the High Power Expert Committee (HPEC) on Investment Estimates in Urban Infrastructure the total investment requirement for the smart city mission would be about ₹ 7 lakh crore over 20 years (with an annual escalation of 10 from 2009-20 to 2014-15) for an average figure of 1 million people in each of the 100 smart cities which translates into an annual requirement of approximately ₹35,000 crore. The central government has proposed to provide financial support amounting to ₹ 48,000 crores, roughly ₹ 100 crores per city per year, over the next five years for the smart cities mission. The respective state governments would also be contributing equally meaning the total financial support extended by the governments would be roughly only ₹1 lakh crore consequently alternative means of funding and large-scale private participation would be required to accumulate necessary funds for the projects.

The alternative means of funding available to the urban local bodies (ULBs) include user charges, PPPs (Public Private Partnerships), land-based fiscal tools such as property taxes and betterment taxes, municipal bonds and loans from bilateral and multilateral organisations. The options available to urban local bodies appear to be plenty, but in terms of the scale of mobilisation of resources, most of these sources are limited. For instance, revenue from user charges for water supply or other civic amenities, even in the best performing municipality, account for only 4 oper cent of the total expenditure due to leakages and unmetered use. Property tax coverage in most cities is not 10oper cent, and the rates are not reflective of the value of the properties. While PPPs bring with them investments from the private sector 
helping bridge the funding gap in addition supplementing limited public sector capacities to meet the growing demand, they are faced by the problem of constructional \& operational risk. There has always been this reluctance from private firms for funding Greenfield developments which have comparatively high risk investments in comparison to Brownfield developments where in the worst case the existing asset can be sold to retrieve capital. Water supply, sanitation and solid waste management projects entail long-term debt and cost recovery is very low and slow because of the population cluster these projects mostly target. The private sector always focus on remunerative returns to sustain their ventures and to overcome the risks involved to ensure return on investment and managing cost escalations while assuring enforcement of contractual terms would require effective monitoring and operational transparency.

There is also a need to develop a vibrant bond market, which includes corporate and municipal bonds. Municipal bonds issued by ULBs need to be developed by providing a robust regulatory framework and possible tax exemption incentives. The infrastructure debt fund is also an option for financing infrastructure projects. A lot of players from foreign capital markets are looking for investment options due to slowdown of other economies and these sources can be effectively tapped.

In our country where typically the government has been the sole financier of infrastructure projects with the responsibility of the implementation, operations and maintenance of these projects which require large scale investment, high initial capital and have long gestation periods mobilising the required financial resources through alternative means for unlaboured infrastructure development is going to be a daunting task to overcome which would require the development of detailed plans by the SPVs and ULBs for structuring the investments with a robust regulatory framework to ensure operational efficiency with minimal interventions and leakages.

\section{Policy Coherence}

Policy Coherence is defined as the systematic promotion of mutually reinforcing policy actions across government departments and agencies creating synergies towards achieving the agreed objectives. India is a country that is eternally caught in the electoral loop it is important to ensure that elections do not shape policies and it is the policies that shape the elections. It is also sadly true that politics and elections are often prioritised over good governance and are regularly the basis of policy making. Elections are often won in our country by focusing on dynamic issues that appeal to domestic constituencies and interests that are not far sighted and do not have broad outreach making the nation's interest often poorly represented and promoted. The lack of coherence in policy and decision making will prove detrimental for the nation when working in a critical era that would shape the future of our country. For the private sector, investments directed towards projects witnessing policy incoherence would be calamitous and is definitely not a risk worth taking. With the Smart Cities Mission aiming to attract large scale private investments it is imperative to ensure policy coherence at all levels.

Progress towards policy coherence can be seen as a three-phase cycle. Phase One in the cycle involves setting policy objectives and determining which objective takes priority if there are incompatibilities between policies. The building block is political commitment expressed at the highest levels and backed by policies that translate commitment into action. Phase Two is policy co-ordination. It involves working out how policies, or the way they are implemented, can be modified to maximise synergies and minimise incoherence. These coordination mechanisms should enable conflicts or inconsistencies between policies to be resolved, and the complex politics of policy processes to be navigated. Phase Three is effective systems for monitoring, analysis and reporting. It involves monitoring, to collect evidence about the impact of policies; analysis to make sense of the data collected; and reporting back to parliament and the public. This phase provides the evidence base for 
accountability and for well-informed policy-making and politics. Combined together the three phases would have to work in sync to ensure policy coherence.

Successful implementation of smart city solutions needs effective horizontal and vertical coordination between various institutions providing various municipal amenities as well as effective coordination between central government, state government and local government agencies on various issues related to financing and sharing of best practices and service delivery processes.

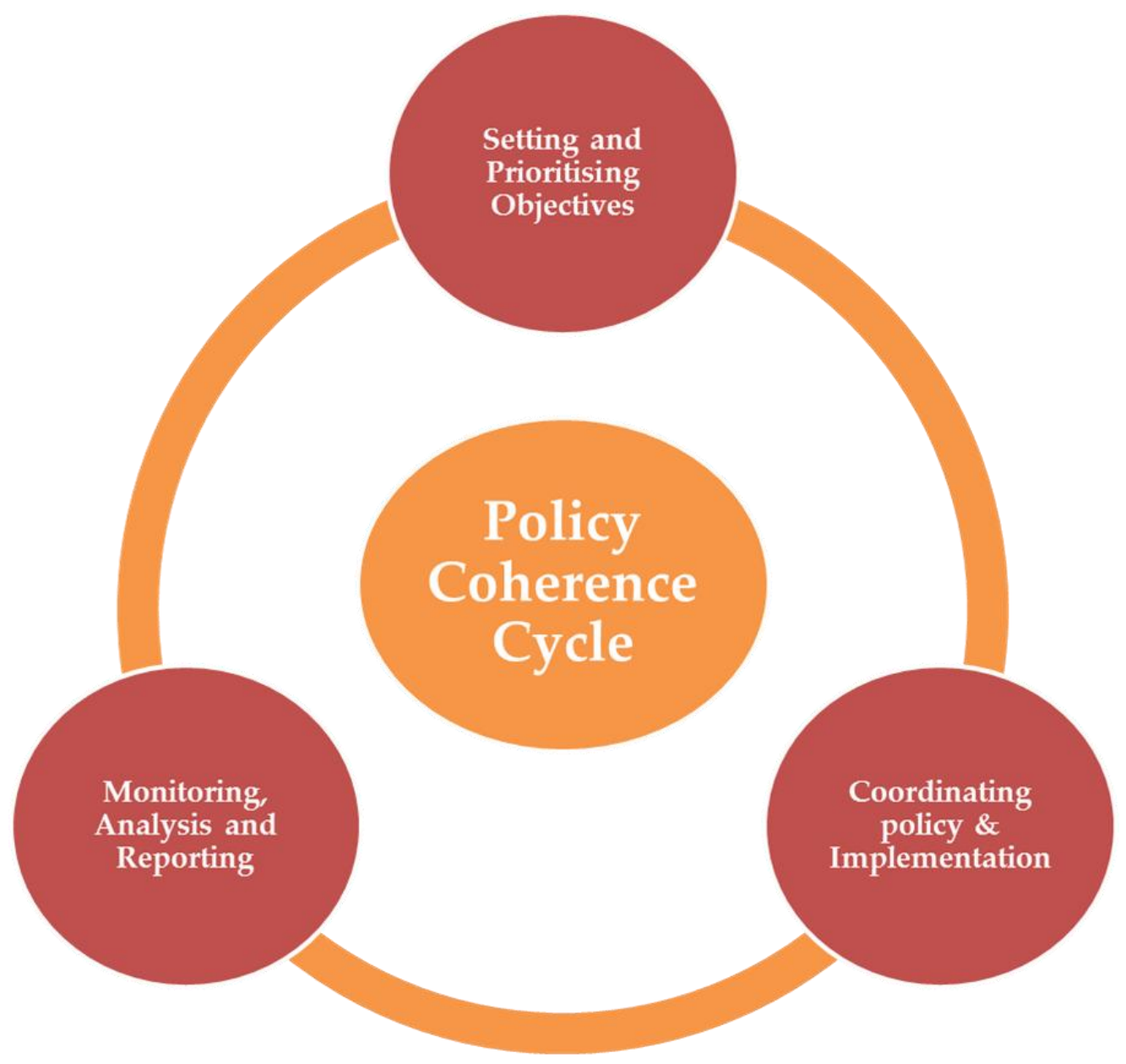

\section{Sustainable Development}

193 countries gathered together at the UN Summit on the Sustainable Development Goals (SDGs), to adopt an ambitious new global development agenda. Along with other world leaders, Prime Minister Modi too expressed India's commitment to work towards achieving these goals by 2030. 'Sustainable Development' as such has three dimensions the environment, the economy and the society. The SDGs have aimed to put forth the most comprehensive list of goals integrating the three dimensions of sustainable development. Some really important agendas like poverty alleviation, total sanitation, clean energy, access to good education which fall under the SDGs have convergence with the existing government agendas which can be synergised to promote comprehensive, inclusive and sustainable development. Achieving the SDGs would require substantial funding along with consistent and concurrent policy frameworks. The large scale urbanisation and development of smart cities have to integrate these principles and aim to achieve all the three dimensions of sustainable development.

While ecological sustainability is one of the key ideals of a smart city managing large scale urbanisation and infrastructure development by integrating the developmental policies with 
the environmental ones in a common framework and implementing it on a large scale is definitely not a challenge that can be undermined. Lot of cities in our country have witnessed unprecedented scales of unplanned urbanisation which have caused widespread damage to natural ecosystems and biodiversity resulting in acute water scarcities, high pollution levels, high carbon footprints, land and soil degradation and many more environmental aggravations. Putting to action a plan to decongest these settlements, revamping them to minimise environmental damage and at the same time ensuring new developments are sustainable is not going be a walk in the park.

Poverty is an elephant in the room with 280 million Indians still living with less than $\$ 1.25$ daily, while the smart cities mission aims to urbanise the nation, growing urban poverty and inequality needs to be addressed to achieve inclusive growth bridging the gap between the poor and the rich. For growth to be inclusive at the micro scale, growth must be inclusive at the macro scale between the states. The evident role of states in influencing economic growth, governance and policies has increasing become more prominent. States are drivers of localised growth, enhancing their own investments, and developing models that are being replicated across the country. More state to state interactions and proactive sharing of knowledge, technology and policies to balance uneven growth between states are necessary to ensure that development is sustainable and inclusive in India as whole and not just in pockets of the nation.

While the Smart Cities Mission embarks on a large scale urbanisation programme integration of the three pillars of sustainable development into national planning and policymaking is a challenging yet unavoidable responsibility to achieve economic growth and social development without compromising on environmental protection to create an India that is truly in harmony with Mother Earth.

\section{Conclusions}

In this increasingly urban world with nearly 600 million people calling urban India their home by 2030, cities have become the centre of society's most pressing economic, social and environmental challenges. They also offer the greatest potential to drive growth and opportunity, large-scale innovation and sustainable solutions. Much has changed though in the external context in which cities have been operating since the 1990s, particularly rising energy prices, natural disasters and environmental accidents, global economic imbalances, security and terrorism threats, and declines in urban social capital.

As India embarks on this ambitious journey to modernise the face of the urban landscape given the tough and increasingly uncertain environment in which cities operate, strategies need to be hard-nosed taking advantage of the latest developments in technology, with a vision of creating employment opportunities and supporting economic activities using limited financial and human resources in the most effective ways. A comprehensive urbanisation strategy prioritizing on improved mobility and access, good urban design, equitable land management and concurrent policy frameworks envisioned to develop integrated infrastructure systems that are sustainable, scalable, flexible and resilient over an extended timeframe can help India's cities can grow efficiently, sustainably and inclusively, transforming urban life across the country and improving the quality of life for millions. 


\section{References}

[1] Census of India 2011. Rural urban distribution of population. Retrieved from http://censusindia.gov.in/2011-prov-results/paper2/data_files/india/Rural_Urban_2011.pdf

[2] McKinsey Global Institute. India's urban awakening: Building inclusive cities, sustaining economic growth. Retrieved from http://www.mckinsey.com/globalthemes/urbanization/urban-awakening-in-india

[3] Ministry of Urban Development, Govt. of India. Smart Cities - Mission Statement and Guidelines. Retrieved from http://smartcities.gov.in/writereaddata/SmartCityGuidelines.pdf

[4] Puri.A. Redevelopment in Metro Cities: A closer look. Retrieved from http://www.moneycontrol.com/master_your_money/stocks news_consumption.php?cat=re alestate\&autono $=918612$

[5] Chanchal Pal Chauhan. Chinese BYD to bring first zero-emission, pure-electric bus in India. Retrieved from http://www.businesstoday.in/sectors/auto/chinese-byd-first-zero-emissionpure-electric-bus-in-india/story/229907.html

[6] Pai. M. What will it take to create smart cities in India? Retrieved from http://wriindia.org/blog/what-will-it-take-create-smart-cities-india

[7] Pal.S. Financing India's smart cities mission: the Special Purpose Vehicle. Retrieved from http://www.teriin.org/index.php?option=com_featurearticle\&task=details\&sid=973\&ltemid= 157

[8] UNDP in India. A New Sustainable Development Agenda. Retrieved from http://www.in.undp.org/content/india/en/home/post-2015/sdg-overview.html

[9] The Brics Post. India's Modi lists poverty as challenge to SDG. Retrieved from http://thebricspost.com/indias-modi-lists-poverty-as-challenge-to-sdg/

[10] Trinity College Dublin. Exploring links between EU agricultural policy and world poverty. Retrieved from https://www.tcd.ie/iiis/policycoherence/concept/what-is.php

[11] Organisation for Economic Co-operation and Development (OECD). Policy Brief: Policy Coherence for Development - Lessons Learned. December 2008. Retrieved from http://www.un.org/en/ecosoc/newfunct/pdf/hls finland-policy coherenceper cent28oecdper cent2g.pdf 